\title{
Performance of concrete with and without crystalline admixtures under repeated cracking/healing cycles
}

\author{
Liberato Ferrara ${ }^{1, *}$, Estefania Cuenca $^{1}$, Antonio Tejedor ${ }^{1}$ and Enricomaria Gastaldo Brac ${ }^{2}$ \\ ${ }^{1}$ Department of Civil and Environmental Engineering, Politecnico di Milano, piazza Leonardo da Vinci, 20133 Milano, Italia \\ ${ }^{2}$ Penetron Italia Ltd., Collegno, Italia
}

\begin{abstract}
The present paper analyses the repeatability of self-healing capacity in fibre reinforced concretes, both autogenous or enhanced by the addition of crystalline admixtures. The behaviour of the investigated concrete mixes was analysed by means of the "Double Edge Wedge Splitting (DEWS)" test, whose configuration and specimen geometry $(150 \times 15 \times 50 \mathrm{~mm})$ allow to predetermine the failure plane and the relative orientation of fibres. Initially, specimens were pre-cracked up to a crack width of $0.25 \mathrm{~mm}$, then they were subjected for 1,3 and 6 months to different exposure conditions, including water immersion, open air exposure and wet/dry cycles After that, specimens were subjected to repeated cracking and healing cycles, alternatively for 1 and 2 months, and up to an overall duration of one year. The crack closure index was evaluated using photogrammetric methods. The results highlighted the potentials of crystalline admixture in guaranteeing a better persistence of the healing performance in the long term and under repeated cracking and curing cycles.
\end{abstract}

\section{Introduction}

The increasing concern for a wise use of construction materials in civil engineering and the need to enhance their in-structure performance has been fostering the development and more and more widespread use of selfhealing cement based materials. Thanks to their ability of partially or completely seal the cracks, which actually stand as an ingress pathway for aggressive agents into concrete, the aforementioned materials can delay the onset of degradation thus contributing to extend the structure service life. Ordinary Portland Cement concrete possesses some autogenous crack sealing capacity, first of all due to the fact that generally, in most cases, up to $20-30 \%$ of cement particles do not complete their hydration process even at later ages. Upon cracking, these un-hydrated cement particles may come into contact with water, if any, or air moisture and undergo delayed hydration reaction whose products, mainly CSH crystals, can contribute to crack closure [1,2]. Moreover, in the vicinity of the same cracks, calcium ions made available by calcium hydroxide produced by cement hydration may also come into contact with carbonate ions, because of carbon dioxide in the air or dissolved in water, and react producing calcium carbonate crystals which also contribute to crack closure. These phenomena are the main causes of the so-called "autogenous healing" [3]. When additions specifically intended to stimulate the healing capacity [4], such as, e.g., crystalline admixtures $[5,6]$ are added to the concrete matrix, the process is denoted as "engineered" or "autonomous healing".
The synergy between self-healing stimulating technologies and dispersed fibre reinforcement has been increasingly investigated in the last years. Fibres, through their capacity of controlling the crack propagation and widening, or even promoting multiple crack formation, can positive interact with the crack sealing/healing phenomena $[1,4,6,8-10]$. Preliminary investigations have in fact shown that cracks up to 30-50 $\mu \mathrm{m}$ width can be healed completely in most cases, such a crack width range being, e.g. characteristic of serviceability stages in High Performance Fibre Reinforced Cementitious Composites (HPFRCCs).

In this framework it is also of the utmost importance to assess whether the self-healing functionality can be guaranteed all along the intended time span against several cracking and healing cycles. This means to assess the repeatability of the self-healing functionality, a topic which has been so far scantly investigated $[7,11]$.

In the last decade, with the progress in image acquisition and analysis methods, several algorithms for the identification and analysis of cracks in concrete structures have been developed [12]. These methods can provide highly precise results, mainly when surfaces with homogenous texture and under homogeneous lighting conditions are analysed [13]. The identification mechanism first of all consists in the application of filters aimed at smoothing and minimizing the errors and sharpening the crack rims, which then proceeds with the identification of the crack. This is most commonly based on binarization algorithms [14] which discriminate each pixel into either white (no crack) or black (crack), based on the definition of a radiometric threshold [15]. This

\footnotetext{
*Corresponding author: liberato.ferrara@polimi.it
} 
produces what is generally known as segmented image. Finally, a further filtering allows the elimination of outliers. The process has to be tailored to the crack parameters which have to be measured, be they crack width, length, depth or area, also looking for the most suitable one to investigate the time evolution of the cracking phenomena. As highlighted by several authors which have employed this kind of methods for crack identification, a precision between $75 \%$ and $95 \%$ can be obtained [16-19].

The main objective of this study consists in the analysis of the repeatability of the crack self-sealing functionality in Fibre Reinforced Concrete (FRC), also as affected by the addition, into the concrete mix, of crystalline admixture as a stimulator of the healing functionality. The evolution of the crack over time, all along the investigated healing period and under the intended healing conditions, will be analysed by means of image analysis methods.

\section{Experimental programme: materials and test methods}

Two different FRC mixes were prepared, respectively without (M1) and with (M2) a commercially available crystalline admixture, whose detailed description can be found in $[20,21]$. The admixture was dosed at $0.8 \%$ by weight of cement, according to proportions shown in Table 1. The main purpose of the fibre addition was the control of the cracking process $[6,22]$.

Table 1. Mix design of investigated FRCs (dosages in $\mathrm{kg} / \mathrm{m}^{3}$ ).

\begin{tabular}{|c|c|c|}
\hline Material & $\begin{array}{c}\text { Without } \\
\text { crystalline } \\
\text { admixture }\end{array}$ & $\begin{array}{c}\text { With } \\
\text { crystalline } \\
\text { admixture }\end{array}$ \\
\hline $\begin{array}{c}\text { Cement CEM II } \\
\text { 42.5 }\end{array}$ & 360 & 360 \\
\hline $\begin{array}{c}\text { Crystalline } \\
\text { Admixture }\end{array}$ & 0 & 2.9 \\
\hline Water & 180 & 180 \\
\hline Superplasticizer & 3.5 & 3.5 \\
\hline Sand 0-4 mm & 814 & 811 \\
\hline Gravel 4-16 mm & 1077 & 1077 \\
\hline $\begin{array}{c}\text { Steel Fibers } \\
\text { Dramix 3D }{ }^{\circledR}\end{array}$ & 40 & 40 \\
$\mathbf{6 5 / 6 0}$ & & \\
\hline
\end{tabular}

Nine prism specimens, 150x150x600 mm, were cast for each mix and tested according to EN 14651 in order to identify the FRC mechanical characteristics. Once tested,

the beams were split into two halves, each of which was cut as shown in Figure 1a to obtain square tile specimens to be employed for Double Edge Wedge Splitting (DEWS) tests (see [23] for a detailed description of the methodology). The employed mix-design allowed to obtain a self-consolidating performance in the fresh state, which, together with the employed beam casting method (Figure 1b) allowed to govern the alignment of the fibres along the length of the same beam specimens. The tile specimens were then grooved and notched so to prearrange the fracture plane (ligament) either parallel $[\mathrm{H} 2, \mathrm{~V} 1, \mathrm{~V} 2, \mathrm{~V} 3]$ or perpendicular $[\mathrm{H} 1, \mathrm{H} 3]$ to the main fibre alignment (Figure 1c).

After four months curing in moist room at $\mathrm{T}=20^{\circ} \mathrm{C}$ and $\mathrm{RH}=95 \%$, the tile specimens were pre-cracked according to the DEWS testing methodology. Tests were performed in crack opening control, assuming as a control parameter the average of the crack opening measured at mid-ligament depth both on the front and rear face of the specimen (Figure 2).

Tests were performed up to an average crack opening equal to $0.25 \mathrm{~mm}$. Upon unloading, the specimens were exposed to three different curing conditions, namely immersion in water, exposure to lab courtyard open air and wet/dry cycles consisting of 4 days in water and 3 days in open air. Different durations of the initial curing period were scheduled, respectively equal to one (specimens FT-1), three (FT-.3) and six months (FT-6). After first curing the specimens were further cracked up to an additional average crack opening of $0.25 \mathrm{~mm}$ and then cured in the same initial conditions for a further period alternatively lasting one or two months. Cracking and curing cycles were repeated up to a total duration of one year. A synopsis of the whole experimental programme is provided in Table 2. As an example, the 23 specimens belonging to the group labelled as FT-6 underwent the following history, for each of the three curing conditions: pre-cracking at $0.25 \mathrm{~mm}, 6$ months curing, further cracking up to additional $0.25 \mathrm{~mm}, 1$ month curing, further cracking up to additional $0.25 \mathrm{~mm}$, 2 months curing, further cracking up to additional 0.25 $\mathrm{mm}, 1$ month curing, further cracking up to additional $0.25 \mathrm{~mm}$ and 2 months curing.

Table 2. Synopsis of experimental results.

\begin{tabular}{lllllllll}
\hline Specimens & \multicolumn{7}{c}{ Healing cycles (months) } \\
\hline FT-6 (23) & & 6 & & 1 & 2 & 1 & 2 \\
FT-3 (20) & 3 & & 1 & 2 & 1 & 2 & 1 & 2 \\
FT-1 (22) & 1 & 2 & & 3 & 1 & 2 & 1 & 2 \\
\hline
\end{tabular}

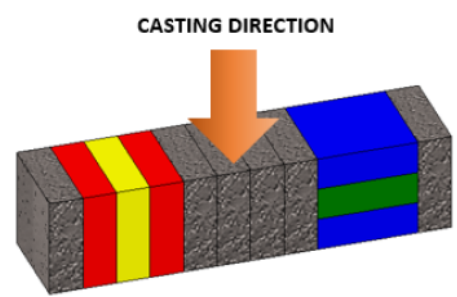

(a)

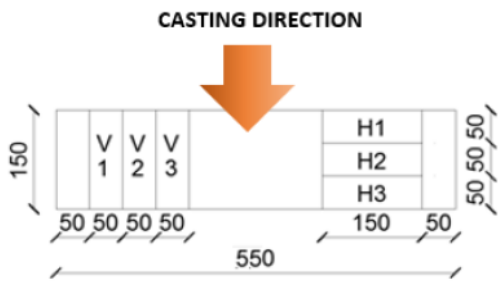

(b)

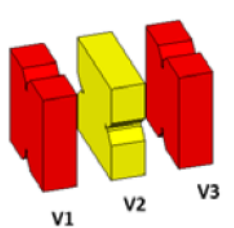

v3

tigation. 


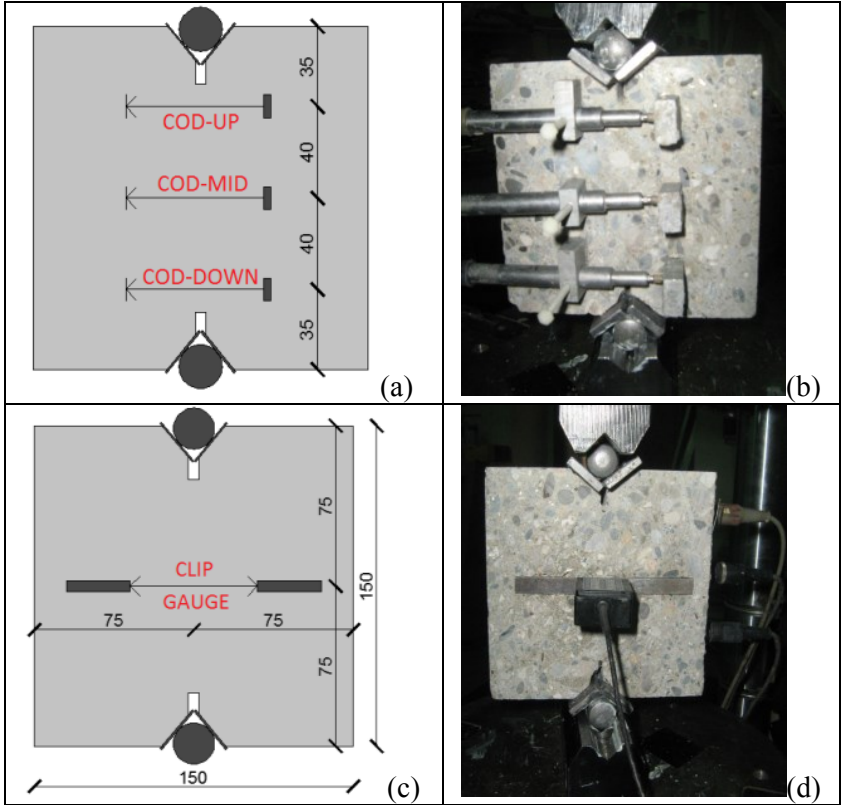

Fig. 2. Geometry (a.c) and set-up details (b,d) of DEWS specimens [front $(a, b)$ and rear $(c, d)$ faces].

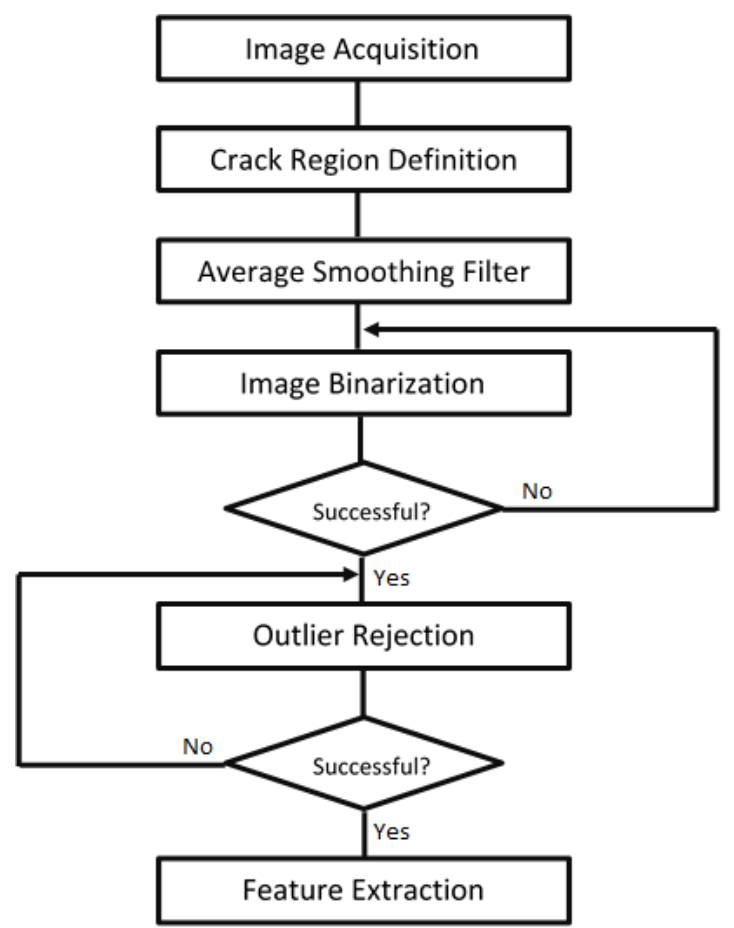

Fig. 3. Image processing procedure

\section{Image processing methodology and crack-sealing quantification}

The sealing of the crack was investigated and quantified by means of image analysis. To this purpose images of the cracks were garnered by means of a digital microscope, all along the ligament of each DEWS specimen. The crack sealing has been quantified by comparing the crack width measurements garnered through the image processing for the same specimen along its curing time. Because of the irregular features of the cracks, an automatic image processing allowing to monitor the crack evolution along its entire length was implemented. The procedure is schematically shown in Figure 3.

In order to analyse the main crack, first of all the zone occupied by it is singled-out (Figure 4a) in order to eliminate secondary cracks, if any, which are not relevant to the investigation, and thus optimize the analysis time. Then, a filter is applied to the image which allows its binarization. Thanks to this process (Figure $4 \mathrm{~b})$ the pixels of the crack can be classified into black or white category (adaptive threshold). Outlier pixels which do not belong to the main crack are then eliminated so that the quantification of the crack area can be performed (Figure 4c).

The process described as above applied to each and all DEWS specimens all along their cracking/healing history will allow to quantify the crack sealing as a function of the exposure conditions and time, through the calculation of crack Sealing Index, defined as below, for $i . t h$ specimen and $j$-th healing cycle.

Sealing Index ${ }_{i}^{j}=\frac{\sum_{1}^{8} C A_{i, p o s t}^{j-1}-\sum_{1}^{8} C A_{i, p r e}^{j}}{\sum_{1}^{8} C A_{i, p o s t}^{j-1}} \cdot 100$

where:

- $\quad \sum_{1}^{8} C A_{i, p o s t}^{j-1}$ is the total crack area (referring the all the 8 pictograms each crack image consists of) for $i$ th specimen, as acquired immediately after the $(j-1)$ th healing cycle;

- $\quad \sum_{1}^{8} C A_{i, p r e}^{j}$ is the total crack area (referring the all the 8 pictograms each crack image consists of) for $i$ th specimen, as acquired immediately after the $j$-th healing cycle.

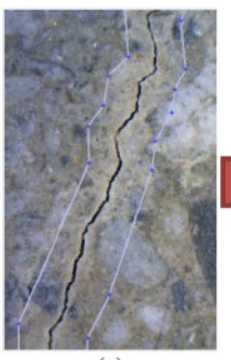

(a)

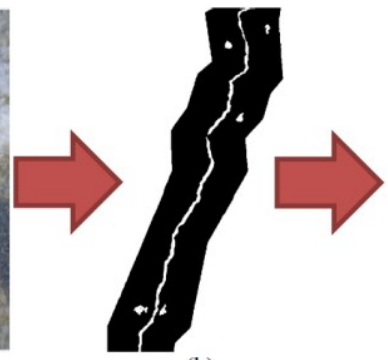

(b)

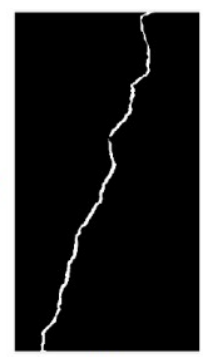

(c)
Fig. 4. Crack imaging and binarization process

In Figure 5 the Crack Sealing Index is shown for all the tested specimens. Their number, together with the different investigated exposure conditions and duration of cracking and healing cycles has resulted in an evidently high dispersion. Anyway it can be clearly observed that the condition most favourable to selfhealing is the continuous water immersion, followed by wet/dry cycles and, finally, by exposure to open air.

As remarked above, cracking/healing cycles extended over a total duration of one year. In Figure 6 the crack sealing indices have been separately plotted for different cracking-healing cycles and separating the results also with reference to initial crack widths. 
Reference has been also separately made to specimens which underwent a first healing cycle of one month (diagrams on the left of Figure 6) and those for which the first healing cycle was prolonged up to six months (diagrams on the right). The influence of the exposure conditions, as also from the global analysis of results in Figure 5, is confirmed. It is also evident that only specimens with cracks narrower than $0.15 \mathrm{~mm}$ when immersed in water were able to achieve complete sealing of the cracks.

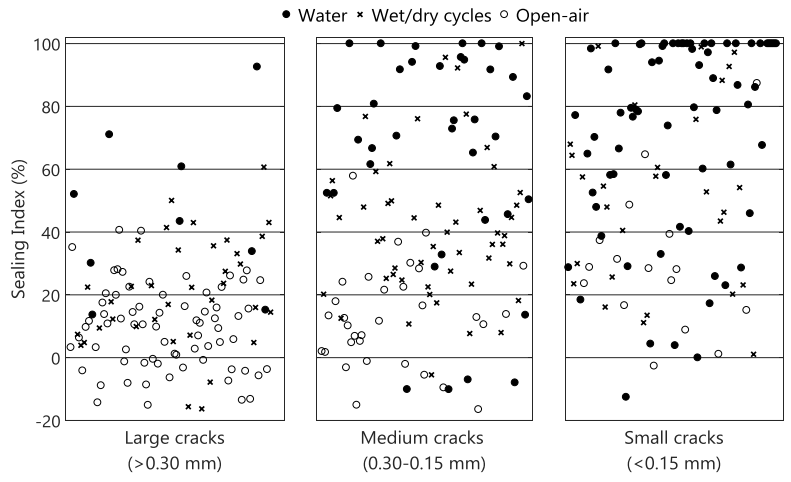

Fig. 5. Crack sealing index for all investigated specimens (both mixes M1 and M2 are considered).

Moreover, a longer first healing (6 months as compared to 1 month) resulted in a better sealing. It is furthermore interesting to observe that specimens with cracks narrower than $0.15 \mathrm{~mm}$ and immersed in water, after twelve months cracking/healing cycles, irrespective of the first healing, achieved complete crack closure. The presence of the crystalline admixture resulted in a faster healing and in a more reliable persistence of the healing functionality after repeated cracking and healing cycles. It is furthermore worth remarking the almost all the specimens with cracks narrower than $0.15 \mathrm{~mm}$ were those immersed in water. This is not surprising if one considers that in most cases those specimens, even after the first cracking and healing treatment, featured almost complete closure of the cracks. This resulted in low or even nil "initial" crack width (at the beginning of each cracking/healing event). On the contrary, specimens exposed to open air featured the lowest crack sealing indices; being the exposure to open air the environment least favourable to healing even cracks initially in the low width range were able to close only partially. Any further cracking/healing event contributed to a progressive increase of the crack width which resulted into a lower and lower crack sealing capacity.

\section{Conclusions}

In this paper a testing and analysis methodology has been proposed to ascertain and quantify the repeatability of the self-healing capacity of fibre reinforced concrete when a crystalline admixture [Penetron Admix $®$ ] is incorporated into the mix. Three different exposure conditions have been considered, including immersion in water, exposure to wet/dry cycles and to open air, all along one year, during which specimens were subjected to repeated cracking and healing cycles. Effects of the duration of the first healing treatment have been also investigated.

The main conclusions of this study hold as follows:

- the exposure condition is the most relevant factor affecting the crack sealing performance. For specimens exposed to open air crack closure indices lower than $20 \%$ were generally recorded, whereas in specimens immersed in water complete crack closure was most frequently observed. This resulted into a progressive opening of the cracks, which the moderate, even if not nil, crack sealing capacity was not able to adequately counteract;

- immersion in water, even non continuous as in wet/dry cycles, was able to trigger almost complete closure of cracks with a width lower than $0.30 \mathrm{~mm}$. This guaranteed that at the end of each healing cycle and before each new cracking event, cracks were almost completely closed, the crack-sealing functionality being thus able to effectively counteracted the repeated cracking;

- the contribution of the crystalline admixture is most significant in specimens immersed in water and with cracks narrower than $0.15 \mathrm{~mm}$. Moreover, its selfhealing stimulating and enhancing effects increase with time, even under repeated cracking and healing cycles. This is likely due to an osmotic migration of fresh crystalline admixture particles, being smaller than cement ones and finer than the pore network they also contribute to refine, from throughout the bulk specimen volume to the crack faces. There they are they are consumed by the healing reactions. Such migration doe not occur for cement particles, the healing functionality of a concrete containing the crystalline admixture thus resulting better than for reference mixture;

- the crack sealing capacity increases with the curing time, even under repeated cracking and healing cycles; in particular, it has been verified that after ten months the influence of the previously undergone treatments tend to vanish and the performance of specimens is likely to be affected only by the total duration of the healing period;

- the repetition of cracking and healing cycles does not affect the healing performance of cracks narrower than $0.15 \mathrm{~mm}$, and with a more evident effect in concrete with crystalline admixture. On the contrary for larger cracks the healing performance tends to decrease upon repeated cracking and healing cycles. Because of the aforementioned osmotic migration phenomena, the crystalline admixture is anyway able to counteract this effect, holding the healing performance almost constant, also for moderately wide cracks (between 0.15 and $0.30 \mathrm{~mm})$.

The second author wishes to acknowledge the PoliMi International Fellowship 2015, for having supported her twoyear post-doctoral stay at Politecnico di Milano, during whose period this study was performed. 


\section{FT-1}

\section{FT-6}

- M1Open-air $\triangle$ M2 Open-air
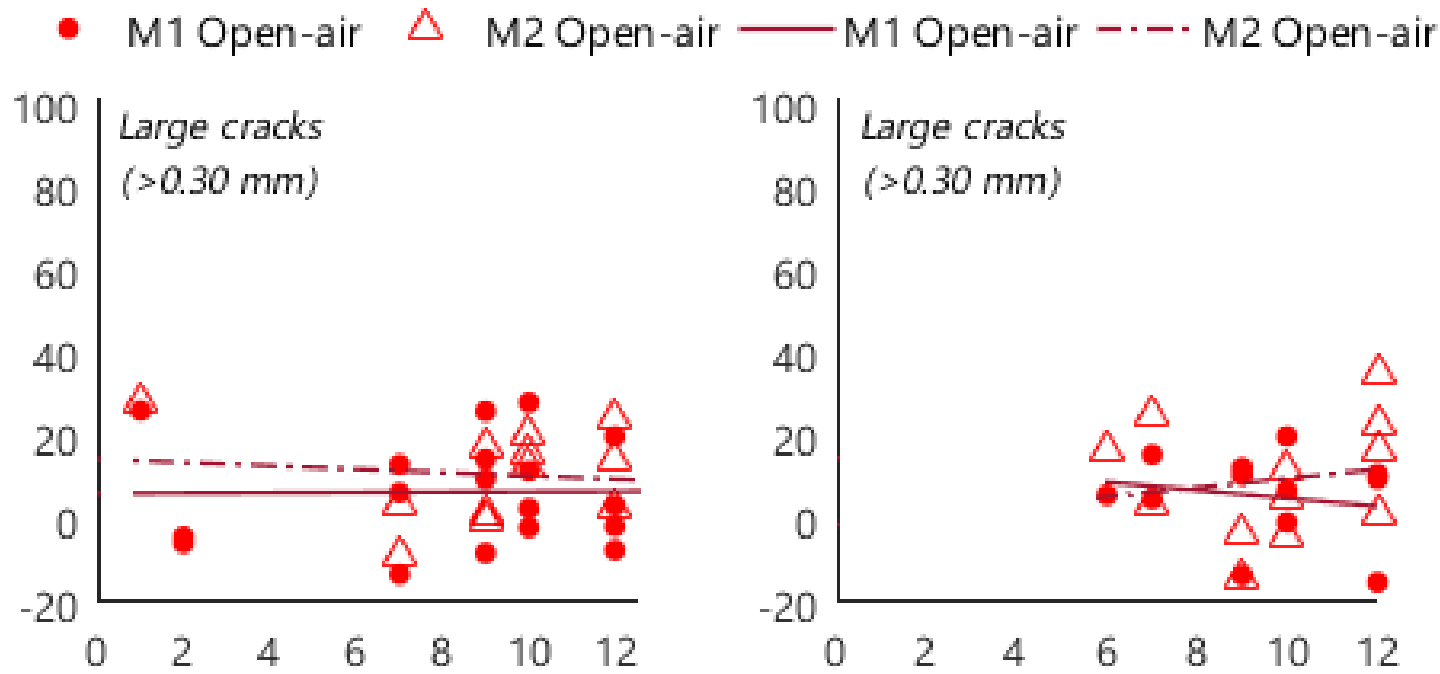
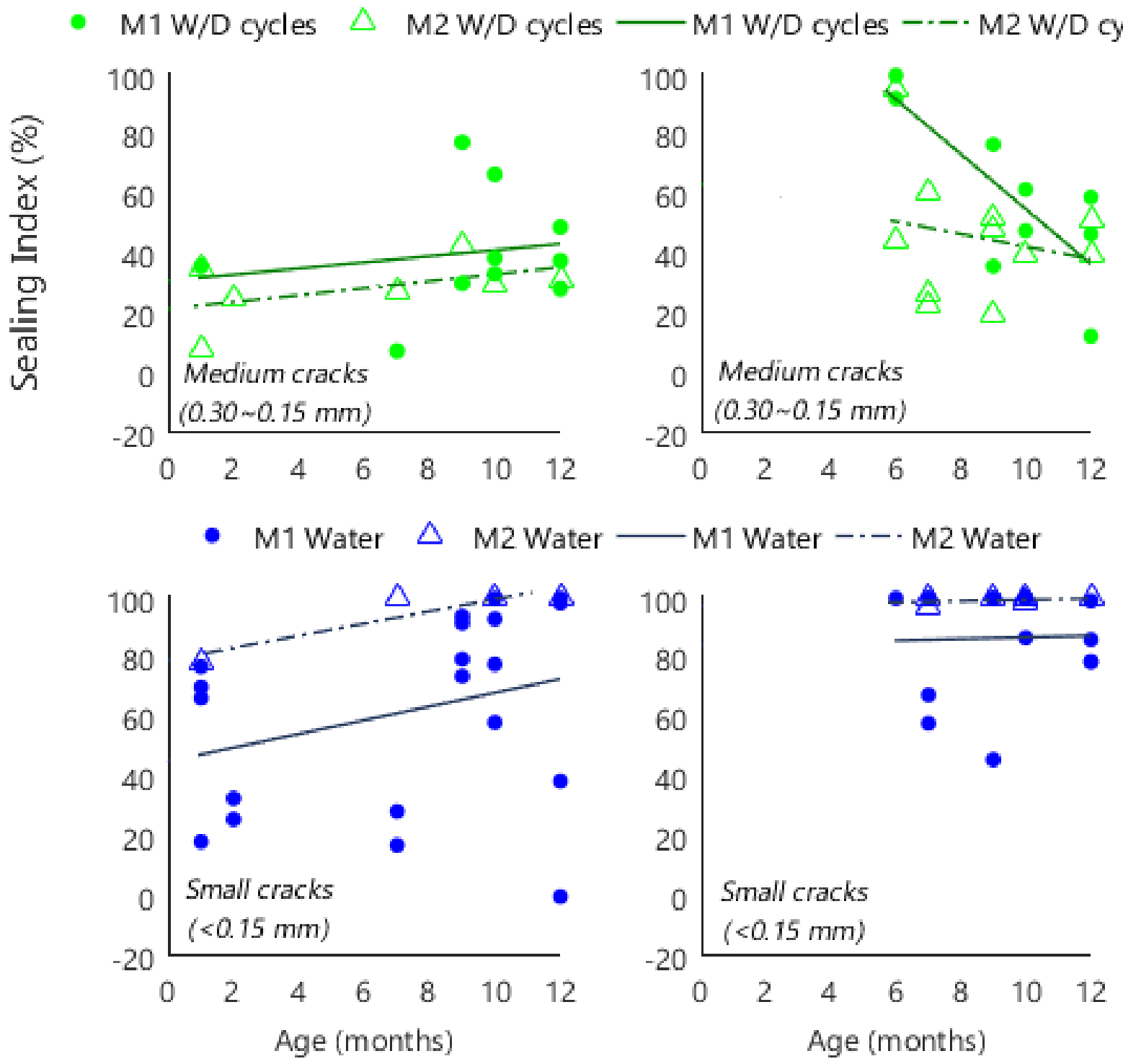

Fig. 6. Crack sealing index along the one-year investigation time-frame as a function of exposure condition and crack width. M1reference concrete - M2-concrete with crystalline admixture. FT-1: specimens undergoing 1 month first healing cycle: FT-6: specimens undergoing 6 months first healing cycle. 


\section{References}

1. Van Tittelboom, K., Gruyaert, E. et al., 'Influence of mix composition on the extent of autogenous crack healing by continued hydration or calcium carbonate formation', Construction and Building Materials 37 (2012) 349-359.

2. Yang, Y., Lepech, M. et al., 'Autogenous healing of engineered cementitious composites under wet-dry cycles', Cement and Concrete Research 39 (2009) 382-390.

3. Ferrara, L., Krelani, V., Moretti, F., Roig-Flores, M., Serna-Ros, P.,' Effects of autogenous healing on the recovery of mechanical performance of High Performance Fibre Reinforced Cementitious Composites (HPFRCCs): Part 1', Cement and Concrete Composites 83 (2017) 76-100.

4. Cuenca E. and Ferrara, L., 'Self-healing capacity of fiber reinforced cementitious composites. State of the art and perspectives', KSCE Journal of Civil Engineering 21 (7) (2017) 1-13.

5. Ferrara, L., Krelani, V. and Moretti, F., 'On the use of crystalline admixtures as promoters of selfhealing in cement based construction materials', Smart Materials and Structures, 25 (8) (2016) 1-17.

6. Roig-Flores, M., Moscato, S et al., 'Self-healing capability of concrete with crystalline admixtures in different environments', Construction and Building Materials 86 (2015), 1-11.

7. Snoeck, D. and De Belie, N., 'Repeated autogenous healing in strain-hardening cementitious composites by using superabsorbent polymers', ASCE Journal of Materials in Civil Engineering 28 (1) (2015) 111.

8. Cuenca, E., Echegaray-Oviedo J. and P. Serna, 'Influence of concrete matrix and type of fiber on the shear behavior of Self Compacting Fiber Reinforced Concrete beams', Composites Part B: Engineering 75 (2015) 135-147.

9. Snoeck, D. and De Belie, N., 'From straw in bricks to modern use of microfibers in cementitious composites for improved autogenous healing - A review', Construction and Building Materials 95 (2015) 774-787.

10. Ferrara, L., Krelani V. and Moretti, F., 'Autogenous healing on the recovery of mechanical performance of HPFRCCs: part 2', Cement and Concrete Composites 73 (2016) 299-315.

11. Sahmaran, M., Yildirim, G. et al., 'Repeatability and pervasiveness of Self-Healing in Engineered Cementitious Composites', ACI Materials J 112 (4) (2014) 513-522.

12. Mohan, A. and Poobal, S. 'Crack detection using image processing: A critical review and analysis', Alexandria Eng. J. (2017).

13. Hutchinson, T.C. and Chen, Z., 'Image-based framework for concrete surface crack monitoring and quantification,' Adv. Civ. Eng. (2010).

14. Imocha Singh, O., Sinam, T., James, O. and Romen Singh, T., 'Local Contrast and Mean Thresholding in Image Binarization,' Int. J. Comput. Appl., 51 (6) (2012) 5-10.
15. Romen Singh, T., Roy, S., and Manglem Singh, K., 'Local Adaptive Automatic Binarisation (LAAB),' Int. J. Comput. Appl., 40 (6) (2012) 27-30.

16. Adhikari, R.S., Moselhi, O., and Bagchi, A., 'Imagebased retrieval of concrete crack properties for bridge inspection,' Autom. Constr., 39 (2014)180194

17. Lee, B.Y., Kim, Y.Y., Yi, S.T., and Kim, J.K., 'Automated image processing technique for detecting and analysing concrete surface cracks,' Struct. Infrastruct. Eng., 9 (6) (2013) 567-577.

18. Fujita, Y., and Hamamoto, Y. 'A robust automatic crack detection method from noisy concrete surfaces,' Mach. Vis. Appl., 22 (2) (2011) 245-254.

19. Valença, J., Dias-Da-Costa, D., Júlio, E., Araújo, H., and Costa H., 'Automatic crack monitoring using photogrammetry and image processing,' Meas. J. Int. Meas. Confed., 46 (1) (2013) 433-441.

20. Ferrara, L., Krelani, V. and Carsana, M: "A fracture testing based approach to assess crack healing of concrete with and without crystalline admixtures", Construction and Building Materials, 68 (2014) 515531.

21. Roig Flores, M., Pirritano, F., Serna Ros, P. and Ferrara, L.: "Effect of crystalline admixtures on the self-healing capability of early-age concrete studied by means of permeability and crack closing tests", Construction and Building Materials, 114 (2016) 447-457.

22. De Nardi, C., Bullo, S., Ferrara, L., Ronchin, L. and Vavasori, A.: "Effectiveness of crystalline admixtures and lime/cement microcapsules in engineered self-healing capacity of lime mortars", Materials and Structures 50 (4) (2017) 191.1191.12.

23. di Prisco, M., Ferrara, L., Lamperti, M.G.L. 'Double edge wedge splitting (DEWS): an indirect tension test to identify post-cracking behavior of fibre reinforced cementitious composites', Materials and Structures, 46 (11) (2013) 1893-1918. 